\title{
Boceprevir increases levels of ciclosporin and tacrolimus
}

Coadministration of boceprevir increases exposure to ciclosporin and tacrolimus in healthy volunteers, according to new research.

The HCV treatment boceprevir can inhibit cytochrome P450 (CYP) 3A4. "As both ciclosporin and tacrolimus are substrates of CYP3A4, we believed that boceprevir could increase ciclosporin and tacrolimus concentrations," explains Ellen Hulskotte, corresponding author from Merck Sharp \& Dohme Corp, The Netherlands.

The open-label, fixed-sequence study included healthy volunteers who were given boceprevir with either ciclosporin (10 people) or tacrolimus (12 people for effects on tacrolimus and 10 for effects on boceprevir). High-performance liquid chromatography-mass spectrometry was used to analyse blood samples for levels of the drugs and their metabolites.
The researchers found that boceprevir increased blood concentrations of tacrolimus and ciclosporin, and speculate that such increases could be greater in recipients of liver transplants, in whom these drugs are used to prevent organ rejection. "Dose adjustments of ciclosporin should be anticipated when administered with boceprevir," suggests Hulskotte. "Administration of boceprevir with tacrolimus is also likely to require dose reduction and a prolonged dosing interval." Close monitoring of patients is recommended if boceprevir is given with either drug.

\section{Andy McLarnon}

Original article Hulskotte, E. et al. Pharmacokinetic interaction between the HCV protease inhibitor boceprevir and cyclosporine and tacrolimus in healthy volunteers. Hepatology doi:10.1002/hep.25831 